\title{
Integration: too much of a bad thing?
}

Yates, R., Burns, J. and McCabe, L.

Integrated and/or multidisciplinary working has become a central guiding principle of addiction treatment throughout the Western world. Indeed, the notion has become virtually synonymous with good practice in intervening in a complex disorder like addiction. There has been surprisingly little analysis or evaluation of the efficacy of this approach. Rather, it is effectively taken for granted that integrated and/or multi- disciplinary working is without question a "good thing". But for complex interventions such as the therapeutic community, it is equally possible that these developments can threaten the underlying principles of the approach. This short literature review considers three areas of integrated working: integrating 'professional staff' into therapeutic community teams; integrating new treatment approaches into existing therapeutic community frameworks; and the issue of therapeutic communities co-working with other treatment services with different philosophies and working practices. The work originated in an evaluative study of a network of Scottish addiction treatment services and the initial findings are that whilst there are some advantages to broadening the horizons of the therapeutic community movement, there is equally a danger of undermining some core principles.

\section{Introduction}

Multi-disciplinary services for the treatment of substance misuse are not a new concept. In the UK, the so-called 'Second Brain Report' (HM Govt., 1965) recommended the attachment of social workers to their proposed 'drug dependency units', which were to be established, almost exclusively within psychiatric hospital settings (Glanz, 2005; Mold, 2004). The Maudsley Alcohol Pilot Project in London in 1975 (Spratley et al, 1977) was one of the first attempts in UK substance misuse treatment to co-ordinate the work of a variety of disciplines involved. Unlike many subsequent attempts, this was seen from the outset as a 'demonstration project', which was intended to mobilise the skills and expertise of generic practitioners working alongside specialists from all the relevant disciplines.

This approach was subsequently taken up and championed by the Advisory Council on the Misuse of Drugs (ACMD) in its 1982 report, Treatment and Rehabilitation (ACMD, 1982), whilst Clement and Strang (2005), in their study of the genesis and development of multi-disciplinary community drug teams argue that the generalisation agenda was largely undermined by: role insecurity amongst generic practitioners; the inadequacy of resources and training provision; and (paradoxically) the dramatic expansion of the 
drug-using population. However, there were considerable successes in the development and promotion of joint-working approaches to the issue (Strang et al, 1991; Strang et al, 1992; Clement and Strang, 2005) and the model was retained and subsequently became seen as, if not the 'gold standard' for drug treatment, certainly an approved and respected option for community-based treatment delivery.

These early explorations of the joint-working paradigm were largely predicated upon other earlier experiments in multi-disciplinary interventions in public health and social welfare. Many of these were in the field of mental health and can be traced back to the work of radical psychiatrists such as Maxwell Jones (Briggs, 2002), Bertram Mandlebrote (Yates, 2003), R. D. Laing (Rawlings and Yates, 2001) and even Bassaglia's Psychiatrica Democratica (Bassaglia, 1988; Wilkinson and Cox, 1986), in moving the treatment of mental health outwith the confines of the psychiatric hospital and addressing its crossdisciplinary nature in community settings.

\section{Methodology}

This brief literature review represents the synthesis of a comprehensive literature search undertaken specifically for this study. The following search terms were used (both individually and in various combinations) ${ }^{1}$ :

- $\quad$ therapeutic communities
- $\quad$ multi-disciplinary addiction teams
- $\quad$ inter-agency working
- $\quad$ interagency leadership
- $\quad$ multi-disciplinary leadership
- $\quad$ multi-disciplinary working
- $\quad$ recovery oriented integrated systems
- $\quad$ recovery oriented systems of care
- $\quad$ public health partnerships
- $\quad$ addictions case management

The following substance misuse specialist databases were searched: Alcohol Concern On-line Library; Alcohol Studies (Rutgers) Database; Archido-Nordic Welfare Council; Beckley Foundation; Centralförbundet för alkohol (Sweden); Drugdata On-line Library (now withdrawn) ${ }^{2}$; Drug Misuse in Scotland (ISD) Publications Database; DrugText; EMCDDA Publications Database; Executive Summaries On-line; Fagibliotek om rus; Ingenta; Lindesmith Center; Medline; National Documentation Centre on Drug Use (Ireland); National Drug Strategy Unit On-line Library (Australia); National Drug \& Alcohol Research Centre On-line Library (Australia); NHS Scotland e-Library; NIDA

\footnotetext{
${ }^{1}$ The list of terms provided here is not exhaustive. A number of other terms were used in various combinations and specific search terms were used to locate "grey" publications by known agencies or individuals.

${ }^{2}$ DrugScope's Drugdata Online Library ceased operation in November 2014. This search accessed the remaining data base which continued to be a significant resource.
} 
Database; Rapid Assessment and Response Archive; Robin Room Archive; Schaffer Library of Drug Policy; Science Direct; Scottish Addiction Studies On-line Library; Social Science Information Gateway; WHO Substance Misuse Database. In addition, the following non-specific academic databases were searched: Psyclnfo; ASSIA; CINHAL; Joseph Rowntree Trust (UK); PubMed; and Web of Science.

The following specialist journals were also searched: Addiction; Addictive Behaviours; Alcohol; American Journal of Drug and Alcohol Abuse; BMC Public Health; Drug and Alcohol Dependence; Drug and Alcohol Review; Drugs Prevention, Education and Policy; Journal of Drug Issues; Druglink; European Addiction Research; Harm Reduction Journal; International Journal of Drug Policy; International Journal of Therapeutic Communities; Mental Health and Substance Use (now ceased publication); Public Health; Journal of Public Health; Social History of Medicine; Journal of Substance Use; Journal of Substance Abuse Treatment; and Drug and Alcohol Findings.

The search was restricted to full text articles in English published between 1990 and $2015^{3}$. Over 600 articles and other publications (monographs, short works, book chapters etc.) were retrieved, with approximately 300 examined in detail.

\section{Therapeutic community methodology}

George De Leon, the first Research Director at Phoenix House New York and a respected authority on therapeutic community (TC) methods, has coined the term community as method to describe the basis of the TC approach (De Leon, 2000). Community is at the heart of the TC approach. The core philosophy is to use the community as a tool to teach the individual member both how to change and how to change others around them. TCs are guided by a perspective consisting of four interrelated views of the substance disorder, the person, recovery and 'right living'4. In the TC view, substance abuse is a disorder of the whole person. Recovery is a selfhelp process of incremental learning toward a stable change in behaviour, attitudes and values of right living, that are associated with maintaining abstinence (Vanderplasschen et al., 2014).

Residents of a TC spend much of their time engaged in structured therapeutic group work, developing practical skills and interests, and (at later stages) in education and training. The aim of the treatment process is to develop self-worth, personal responsibility and life and social skills with the goal of achieving long-term abstinence and reintegration into the community and into employment. The hierarchy (or structure) of the community is demonstrated through individual job functions and is designed to look like work in the real world (Kooyman, 2001). Progression up the hierarchy of job functions is much like the movement up the occupational ladder in the real world.

The hierarchy and the daily work programme (sometimes described as 'floorwork') are

\footnotetext{
${ }^{3}$ A small number of publications were included which lay outside these parameters where their inclusion was felt to provide an important historical perspective.

${ }^{4}$ This is another concept expounded by De Leon and refers to a state of pro-social positive citizenship. De Leon argues that this - rather than sobriety is the ultimate goal of the TC; with abstinence being merely a side-effect.
} 
used to provide community members with goals, targets and tangible rewards for improved attitude and behaviour. Groups are used both to counter-balance the tensions elicited during floorwork and to reinforce positive behaviour and challenge negative attitudes. Movement through these stages is facilitated by group work, modelling from senior residents, key-work sessions focusing on individual issues, and through work opportunities. The ultimate goal of the hierarchy within the TC is personal growth, with job functions teaching positive attitudes and values (Yates and Raimo, 2002).

Over the years, the TC, in most countries has changed from being a purely self-help, addict/ex-addict run intervention to employing professional staff from a variety of disciplines including psychiatry, psychology, social work, nursing, occupational therapy etc. in order to create multidisciplinary staff teams. In parallel with this development, the TC has increasingly incorporated other approaches including anger management, cognitive behavioural therapy, relapse prevention classes etc. In some cases, this has been at the behest of service commissioners at either local or national government level whilst in others, new approaches have been enthusiastically pioneered by TC staff teams. Finally, with the increasing recognition of addiction as a multi-faceted and, generally, long-term disorder, impacting upon a range of health, social and welfare sectors, there has been a rapid growth in partnership or co-working arrangements between various agencies both generic and specialist. These three developments have generally been seen as positive moves towards a holistic response although some (Yates and Raimo, 2002; De Leon, 2010a; Yates, 2015) have argued that they may have the potential to undermine the fidelity of the TC model and have pointed to the surprising dearth of evaluative studies on this question.

It is these three areas - the emergence of multi-disciplinary teams within TCs, the integration of new treatment elements into the TC methodology and the development of co-working to provide multi-agency responses - which this literature review attempts to examine and evaluate.

\section{Multi-disciplinary Working}

In child protection in particular, the need for multi-disciplinary and/or multi-agency working has been regularly revisited with varying success. Stanley and Humphrey (2006) have described a continuum of joint-working (both within and between agencies) in this area, and argued for more - and deeper - integration, but they have also acknowledged the work of Glisson and Hemmelgarn (1998) in the USA who argued that lower levels of inter- and intra-organisational co-ordination actually reduced service effectiveness and that an improved 'organisational climate' (reduced staff conflict, increased co-operation and personal discretion and improved role-clarity) were of more importance than organisational and/or cross-disciplinary arrangements. Hague, Mullender and Aris (2003) similarly argued in respect of responding to issues of domestic violence, that increasingly elaborate nature of such arrangements often fail to improve the accountability of services, although a subsequent study by one of the authors suggested that where multi-disciplinary working is implemented in an organic way with adequate training and consultancy, the resulting outcomes can exceed those of single agency interventions (Mullender, 2004). 
These apparently differing views of the value of joint working do share some common findings. Like both Hague, Mullender and Aris (2003) and Glisson and Hemmelgarn (1998), Wills and Ellison (2007), in reporting on their detailed analysis of a multidisciplinary workshop, highlighted differing cultures across agencies and disciplines as a crucial factor in improving joint working and noted:

"The workshop exposed an extraordinary degree of misunderstanding about the roles of each of the organisations' constituent services. Participants from each of the services saw their 'core business' as separate from that of the other services. 'Core business' was characterised by the specific functions and duties carried out exclusively by each service, based partly on (perceived) differences in expertise, and partly on different statutory responsibilities."

(Wills and Ellison, 2007, 547)

In therapeutic communities, multi-disciplinary working has its origins in the introduction of the concept to Europe, where it was effectively merged with the already existent 'democratic' therapeutic tradition of Jones, Mandelbrote and Laing (Rawlings and Yates, 2001; Broekaert et al, 2006), a largely psychiatry-led movement. Thus in Europe, therapeutic communities, from the outset were multi-disciplinary; including both health service staff and graduates of the programme. In the USA also, state sponsorship of therapeutic community approaches led inexorably towards the development of such multi-disciplinary teams (De Leon, 2000; Yates and Malloch, 2010). Much of the professionalising of therapeutic communities over the past three decades can be attributed to the demands of commissioning agencies (and many professionals), sceptical about the efficacy of a purely self-help treatment intervention. The negative views of mainstream treatment providers towards initiatives such as AA/NA and therapeutic communities is well documented (De Leon, 2000; Best et al, 2000; Yates, 2015).

This of course, is not to say that including professional practitioners in therapeutic community staff teams is wrong but it does require a significant philosophical shift for trained professionals to recognise and internalise the fact that in a therapeutic community they operate as a member of the community and not as a professional dispensing treatment and advice (De Leon, 2000; Yates and Malloch, 2010).

\section{New Treatment Approaches}

In therapeutic communities, this lack of conviction and basic understanding of the model has often led to the imposition by commissioners and/or implementation by professional practitioners, of practices which are not only unnecessary but are occasionally undermining of the core philosophy of community as method (De Leon, 2000; Yates and Raimo, 2002; Yates, 2003).

From its earliest days, the therapeutic community has been the crucible of much innovative therapeutic work. It was this movement that promoted dramatherapy, psychodrama, bonding therapy, scream therapy etc. in addictions treatment. That these practices are now effectively unknown and unused in the therapeutic community world is telling. In part, their disappearance is the result of the best elements being subsumed 
(and reconfigured) within the community as method approach. In part too, this process has been extremely instructive in exploring the core principles and their capacity for modification. Where perhaps the therapeutic community movement has signally failed is in its failure to secure a wider understanding of the approach as a complex, viable and complete method in itself.

This failure has inevitably led to attempts - either imposed by commissioners or championed by individuals within the movement - to graft new approaches onto the system; often with unintended and largely negative results. Thus, for instance, the past two decades has seen a dramatic increase in keyworker systems and other one-to-one interventions without apparently recognising that this undermines community as method by increasing the amount of information which is unavailable to the community. Similarly, anger management interventions (Howells and Day, 2003) have been introduced into therapeutic communities, apparently without recognising that the floorwork element of therapeutic community methodology is - at least in part designed to instil precisely this capacity.

Whilst it is certainly not advocated that therapeutic communities should close themselves off from new and innovative ideas: indeed the experience of De Kiem in establishing a Welcome House and easing new members into their therapeutic community has had significant impacts on retention in the main programme (Vanderplasschen et al, 2014) and has been successfully emulated in other therapeutic communities (Phoenix Futures, 2011). But it is also clear that great care should be taken in introducing new elements into a complex intervention to avoid the risk of what De Leon (2010a) has described as the erosion or undermining of "the fidelity of communityas-method".

Moreover, there is the simple question of time. A functioning therapeutic community as described here, relies heavily upon a careful counterbalancing of groupwork and floorwork. Far too often, floorwork is dismissed as activity to occupy residents while they wait for their next groupwork intervention, rather than the crucible within which frustrations and poor behaviour are elicited as material for the community to work upon in the groups Yates and Raimo, 2002). Far too often, it is this floorwork element which is squeezed in order to incorporate new interventions; running the risk of fatally undermining the balance between these two critical elements.

\section{Co-working with other agencies}

It is clear, from the work of Glisson and Hemmelgarn (1998) and Stanley and Humphrey (2006) that co-working between agencies has the potential to deliver significant improvements in service outcomes. However, it is also clear that such arrangements are beset with problems; not least the often striking differences in core philosophy and organisational culture (Vandeplasschen et al, 2007; Yates, 2015). It would appear that a crucial element in the development of joint working projects will be a common understanding of the nature of the issue to be addressed; the expertise and experience to be brought to bear upon the issue by the significant players; and a shared vision of the possible outcomes. These are issues which are raised as "crucial elements" by De Leon (2007) in the description of his 'Recovery Oriented Integrated Systems (ROIS); a 
concept which De Leon has pioneered within the US prison system. Discussing ROIS, De Leon notes:

"These TC concepts offer insights for developing systems of continuity of care, which are integrated to sustain the individual in the recovery process."

(De Leon, 2010b, 79-80).

What is required as a starting point, De Leon argues, is a 'common vernacular' which ensures that all staff involved have a common understanding of the agreed goals in each individual case and a shared understanding of the meaning of the words used to describe them. De Leon is critical of the organisational separation he observed in the US criminal justice system (both custodial and post-release) and argued that the failure to appropriately co-ordinate services was costly both in terms of finances and outcomes:

"A poorly coordinated and conceptually unrelated system leads to duplication or lack of services, non-utilisation or poor utilisation of services, cost inefficiency, and often wasteful professional and agency turf conflicts."

(De Leon, 2007: 82)

De Leon's ROIS was initially taken up in the UK by a range of service planners and providers in North-West England (Gilman and Yates, 2010; Gilman and Yates, 2011). However, these developments were superceded (initially in the US and subsequently in the UK) by the development of 'Recovery Oriented Systems of Care' (ROSC). ROSC appears to have emerged initially out of the work of recovery commentator-activists such as William White and Arthur Evans, both of whom were active in setting up and developing new integrated treatment systems mainly in Philadelphia; most notably in the Dawn Farm long-term residential rehabilitation facility in that area (White, 2000; Evans et al, 2007; White, 2007). The similarities between ROIS and ROSC are striking. Both argue for a view of treatment as part of a long-term investment in recovery. Both evidence the advantages of joint-working. And both argue for a system of services built to deliver sustainable long-term recovery.

For therapeutic communities, this raises the question of effective co-working with agencies which may not share the therapeutic community's 'disorder of the whole person' view of addiction. Paradoxically, providers of long-term methadone maintenance will generally profess an adherence to Zinberg's bio-psychosocial model of addiction (Zinberg, 1984) although their practice may appear more in line with the long since discredited disease model (Jellinek, 1952; Trice and Wahl, 1958). Conversely - but equally confusingly - AA/NA argue for the disease model despite the fact that their practical application of the 12 steps would appear to owe more to Zinberg (Bamber et al, 2011; Yates, 2015) withg their emphasis on changing social networks and changing behaviour as well as maintaining sobriety.

With the enforced foreshortening of residential treatment programmes: often in direct contradiction of the evidence base on the relationship between treatment duration and positive outcome, therapeutic communities are more and more relying upon co-working arrangements with agencies/entities which can provide post-programme support. In particular, the past decade has seen an increasing reliance upon the use of the 12 step 
fellowship to provide after-care support. This is understandable of course, in light of the therapeutic communities origins in the fellowship (Rawling and Yates, 2001; Yates and Malloch, 2010; Goethals et al, 2011), but it should be born in mind that the movement split from the fellowship as a result of some quite profound differences in view. Notable amongst these would be the fellowship's disquiet regarding 'cross-talking' (a direct contradiction to the encounter group practices of therapeutic communities) and the quite different view of the nature of addiction. Whilst in practice, some of these differences may be less stark in applied practice than in theoretical position, it is important - given the reliance of the therapeutic community on the community itself to generate an understanding of recovery - that these differences are clearly understood and accepted, by individual therapeutic community members moving between the two.

\section{Summary}

The evidence base around integrated systems for substance misuse and recovery treatment can be both confused and confusing. However, it is clear that a number of findings remain consistent throughout. Firstly, integrating systems of care in response to such a complex socio-medical issue as substance misuse, requires a great deal of thought and even more commitment. In particular, attention must be paid to the issue of organisational climate and the development of a common vision, language and above all, philosophy. Where there are fundamental differences, it is important that these be explored and mutually understood (if not resolved).

Secondly, the therapeutic community movement itself needs to develop a greater evaluative and evidence-based understanding of its own practice in order to understand and predict the impact of changes and additions made to what is an extremely complex and delicately balanced system of responses to addictive behaviour.

Thirdly, much of the evidence found during this literature search and review is not only contradictory: very little was found which related specifically to the addictions field. There is a clear need to focus on this area of interest in the future. An assumption that positive benefits found in other fields of social welfare can be automatically transferred to the addictions field or, worse, that these areas of integration are self-evidently positive is simply not acceptable.

Finally, it is clear that the current shift across much of Europe - both within therapeutic communities and within the wider drug treatment field - from an acute care model to one of recovery management within a bio-psychosocial paradigm will require specialist agencies both to reposition themselves along a continuum of need and to be more open to a shared care agenda which incorporates a wider range of partners (including service users themselves) offering a broad spectrum of advice, support, activities, education and companionship. 


\section{REFERENCES}

Advisory Council on the Misuse of Drugs Government (1982): Treatment and Rehabilitation. London: HMSO.

Bamber, S., Best, D., Gilman, M., Groshkova, T., Honor, S., McCartney, Mercer, T., Wisely, C., Yates, R. White, W. (2011) Recovery and straw men: an analysis of the objections raised to the transition to a recovery model in UK addiction services, Journal of Groups in Addiction and Recovery, 5, 264-288

Basaglia, F. (1988) Italian psychiatric reform as a reflection of society. In, S. Ramon and M. Giannichedda, eds. Psychiatry in Transition: The British and Italian experiences, London: Pluto Press, 273-281.

Best, D., Harris, J. \& Strang, J. (2000). The NHS AA/NA: NHS attitudes to 12 step help. Addiction Today, 11, 17-19.

Briggs, D. (2002) A Life Well Lived: Maxwell Jones - a memoir. London: Jessica Kingsley.

Broekaert, E., Vandervelde, S., Soyez, V., Yates, R. \& Slater, A. (2006). The third generation of therapeutic communities: the early development of the TC for addiction in Europe. European Addiction Research, 12, 2-11.

Clement, S. and Strang, J. (2005) The rise and fall of the community drug team. In: J. Strang, and M. Gossop, eds. Heroin Addiction and Drug Policy: The British System Volume 1, Oxford: Oxford University Press, pp. 94 - 104.

De Leon, G. (2000) The Therapeutic Community: theory, model and method. New York: Springer Publishing Company.

De Leon, G. (2007) Towards a recovery oriented integrated system. Offender Substance Abuse Report, 19 (5), pp. 478-494.

De Leon, G. (2010a). Is the therapeutic community an evidence-based treatment? What the evidence says. International Journal of Therapeutic Communities, 31(2), 104-128.

De Leon, G. (2010b). The therapeutic community: a recovery oriented treatment pathway and the emergence of a recovery oriented integrated system. In: R. Yates \& M. Malloch eds. Tackling Addiction: Pathways to Recovery. London: Jessica Kingsley, pp. 7083.

Evans, A., White, W., Schwartz, J., Adson, A., Weiner, H., Lanza, J., Collins, W., BostonJones, L., Fish, L., Morgan, C. and Pettit, L. (2007) The Role of Clinical Supervision in Recovery Oriented Systems of Behavioral Healthcare. Philadelphia: Philadelphia Department of Behavioral Health and Mental Retardation Services.

Gilman, M. and Yates, R. (2010) NW ROIS: Recovery oriented integrated systems in North West England. In: R. Yates and M. Mallcoh eds. Tackling Addiction: Pathways to recovery. London: Jessica Kingsley Publishers, pp. 84-95. 
Gilman, M. and Yates, R. (2011) North West Recovery Forum: recovery and harm reduction, the odd couple of drug treatment? Journal of Groups in Addiction and Recovery, 6 (1), pp. 49-59.

Glanz, A. (2005) The fall and rise of the general practitioner. In: J. Strang, and M. Gossop, eds. Heroin Addiction and Drug Policy: The British System - Volume 1, Oxford: Oxford University Press, pp. 53 - 67.

Glisson, C. and Hemmelgarn, A. (1998) The effects of organizational climate and interorganizational coordination on the quality and outcomes of children's service systems. Child Abuse and Neglect, 22 (5), pp. 401-421.

Goethals, I, Yates, R., Vandervelde, S., Broekaert, E. and Soyez, V. (2011) A religion too far: on the hidden ideology of a social therapeutic belief system, Mental Health and Substance Use, 4(3), 177-194.

Hague, G., Mullender, A. and Aris, R. (2003) Is Anyone Listening? Accountability and women survivors of domestic violence. London: Routledge.

HM Government (1965): Second Report: Interdepartmental Committee on Drug Addiction. London: HMSO.

Howells, K and Day, A. (2003) Readiness for anger management: clinical and theoretical issues, Clinical Psychology Review, 23(2), 319-337.

Jellinek, E. (1952). Phases of alcohol addiction. Quarterly Journal of Studies on Alcohol, $13,673$.

Kooyman, M. (2001) The history of therapeutic communities: a view from Europe. In: B. Rawlings and R. Yates eds. Therapeutic Communities for the Treatment of Drug Users. London: Jessica Kingsley Publishers, pp. 59-78.

Mold, A. (2004) The 'British System' of heroin addiction treatment and the opening of drug dependence units, 1965-1970. Social History of Medicine, 17 (3), pp. 501-517.

Mullender, A. (2004) Tackling Domestic Violence: providing support for children who have witnessed domestic violence. London: Home Office.

Rawlings, B. and Yates, R. (2001) Fallen angel. In: B. Rawlings and R. Yates eds. Therapeutic Communities for the Treatment of Drug Users. London: Jessica Kingsley Publishers, pp. 9-28.

Spratley, T., Cartwright, A. and Shaw, S. (1977) Planning for the future: developing a comprehensive response to alcohol abuse in an English health district. In: J. Madden, R. Walker and W. Kenyon eds. Alcoholism and Drug Dependence: A Multi-disciplinary Approach. New York: Plenum Press, pp. 379-386. 
Stanley, N. and Humphreys, C. (2006) Multi-agency and multi-disciplinary work: barriers and opportunities. In: C. Humphreys and N. Stanley eds. Domestic Violence and Child Protection: directions for good practice. London: Jessica Kingsley, pp. 177-194.

Strang, J., Donmall, M., Webster, A., Abbey, J. and Tantam, D. (1991) A Bridge Not Far Enough: community drug teams and doctors in the North West Region, 1982-1986. London: Institute for the Study of Drug Dependence.

Strang, J., Smith, M. and Spurrell, S. (1992) The community drug team: data and analysis. British Journal of Addiction, 87 (2), pp. 169-178.

Trice, H. and Wahl, J. (1958). A rank order analysis of the symptoms of alcoholism. Quarterly Journal of Studies on Alcohol, 19, 636.

Vanderplasschen, W., Mostien, B., Franssen, A., Lievens, K., De Maeyer, J. and Broekaert, E. (2007) Dealing with multiple and frequent service utilisation in substance abuse treatment: experiences with coordination of care in residential substance abuse agencies in the region of Ghent, Belgium. International Journal of Therapeutic Communities, 28(1), 74-89.

Vanderplasschen, W., Vandevelde, S. and Broekaert, E. (2014) Therapeutic Communities for Treating Addictions in Europe: Evidence, Current Practices and Future Challenges. Lisbon: European Monitoring Centre for Drugs and Drug Addiction.

White, W. (2000) Towards a New Recovery Movement. Arlington: Center for Substance Abuse Treatment.

White, W. (2007) Addiction recovery: Its definition and conceptual boundaries. Journal of Substance Abuse Treatment, 33 (3), pp. 229-241.

Wilkinson, K. and Cox, A. (1986) Principles into Practice: a developmental study of a community mental health service, Manchester: Youth Development Trust.

Wills, J. and Ellison, G. (2007) Integrating services for public health: challenges facing multidisciplinary partnership working. Public Health, 121 (7), pp. 546-548.

Yates, R. and Raimo, S. (2002) A Precious Inheritance: The Evaluation of Coolmine House. Dublin: Coolmine TC. doi:

http://www.dldocs.stir.ac.uk/documents/coolminereport.pdf

Yates, R. (2003) A brief moment of glory: the impact of the therapeutic community movement on drug treatment systems in the UK, International Journal of Social Welfare, 12 (3), pp. 239-243. 
Yates, R. and Malloch, M. (2010) The road less traveled? a short history of addiction recovery. In: R. Yates and M. Malloch eds. Tackling Addiction: Pathways to Recovery. London: Jessica Kingsley.

Yates, R. (2015) Recovery capital, addiction theory and the development of recovery communities. Addicta, 1(2), pp. 96-112.

Zinberg, N. (1984) Drug, Set and Setting: The basis for controlled intoxicant use. New Haven: Yale University Press. 